\title{
The effect of perspective taking on the mediation process
}

\section{Stefano Boca \\ Maria Garro \\ Isabella Giammusso \\ Costanza Scaffidi Abbate}

Department of Psychology, University of Palermo, Palermo, Italy
Correspondence: Costanza Scaffidi Abbate

Department of Psychology, University of Palermo, Edificio I5, Via delle Scienze, Palermo, 90100, Italy

Email costanza.scaffidi@unipa.it
This article was published in the following Dove Press journal: Psychology Research and Behavior Management

Background: Previous research demonstrated several benefits of strategic perspective taking in the field of intergroup relations and, more specifically, in the negotiation processes aimed at conflict resolution. The present study, which analyzes the effect of perspective taking and mediation in a conflict setting, corroborates the psychological models that hypothesize the positive effects of the assumption of the competitor's perspective on having intergroup conflict and lessening of negative consequences.

Materials and methods: After being involved in an epistolary debate on a topic for which their ingroup had very contrasting views compared to an outgroup, participants were asked to use a feeling thermometer to assess their level of intergroup hostility. Mediation was then used as a conflict-resolution strategy for half of the participants. Furthermore, the assumption of perspective was manipulated, resulting in a 2 (conflict: presence vs absence) $\times 2$ (perspective taking: presence vs absence) $\times 2$ (mediation: presence vs absence) between-subjects design. Finally, participants were asked to use the same feeling thermometer to evaluate whether feelings of hostility diminished.

Results: The results show that in conflict situations, the level of hostility decreases the most when the mediation process is accompanied by perspective taking.

Conclusion: The results extend recent results about the advantages of a significant social ability - perspective taking - for improving intergroup relations.

Keywords: perspective taking, mediation, conflict resolution, intergroup conflict, racial bias

\section{Introduction}

Perspective taking is the cognitive ability to look at the world from another person's perspective, which "allows an individual to anticipate the behavior and reactions of others." The capacity to assume the perspective of another person has been recognized as an important factor in social functioning that increases empathic attitudes and diminishes the amount of category-based responses toward outgroup members. ${ }^{1,2}$ Piaget asserted that the skill to modify perspectives is a key step in cognitive development. ${ }^{3}$ Davis found that perspective taking is directly related to social competence and self-esteem. ${ }^{1}$ In addition, perspective taking can promote helping behavior and reduce false-consensus effects. ${ }^{4-8}$ Finally, researchers have related the lack of perspective taking to social dysfunction and aggressive behavior. ${ }^{9,10}$

The present study deepens the recent literature about the relative benefits of perspective taking in the domain of intergroup conflict.

Previous research demonstrated several benefits of strategic perspective taking in the field of intergroup relations and, more specifically, in the negotiation processes 
aimed at conflict resolution. ${ }^{11,12}$ In regard to the first aspect, researchers have determined the efficacy of perspective taking as a strategy for discrimination denial and the reduction of intergroup prejudice, both for positive explicit intergroup evaluations and even for implicit racial evaluations and attenuation of automatic expressions of racial bias. ${ }^{13-17}$ For a review, see Todd and Galinsky. ${ }^{18}$

As for what is concerned in the negotiation process, Bazerman and Neale affirmed that "taking the perspective of an opponent is not done for purely philanthropic reasons; rather, in achieving any set of objectives, there is valuable information to be gleaned from taking the perspective of the other negotiating party." "11 The authors of several practical guidebooks have considered perspective taking to be a valuable strategy that helps negotiators to reach satisfying agreements. ${ }^{19}$

In support of this hypothesis, Galinsky and Mussweiler, for example, showed that perspective taking is a potent instrument for getting over cognitive barriers, such as anchor effects, in negotiations. ${ }^{20}$ Bazerman and Neale and Galinsky et al demonstrated that negotiators who took their counterparts' perspective both increased their individual outcomes and succeeded in creating more value for the counterpart in an integrative negotiation task, that is, an integrative agreement which reconciles the interests of both parties and leads to higher joint benefit. ${ }^{11,21-23}$

Beyond highlighting the relative benefits of perspective taking in intergroup evaluations and behaviors, researchers have also deepened the study of the mechanisms underlying intergroup perspective taking. In their review, Todd and Galinsky suggested that perspective taking may have a positive effect on intergroup outcomes through both affective and cognitive mechanisms. ${ }^{18}$ On the affective side, in fact, several researchers have documented increased empathic responding following perspective taking. ${ }^{24-26}$ On the cognitive side, two different processes have been proposed: shifts in attributional style and self-outgroup merging. The former refers to a change in attributional style - specifically, stronger non-dispositional attributions and weaker dispositional attributions - following perspective taking. Vescio et al, for example, showed that perspective taking increases judgments relying on non-dispositional factors in the explanation of negative outgroup behaviors. ${ }^{15,26}$

The latter, self-outgroup merging, refers to an overlap in mental representations of the self and the other. Todd and Burgmer suggest an associative self-anchoring account of automatic intergroup evaluation change following perspective taking. ${ }^{17}$ This account entails a causal sequence whereby adopting an outgroup member's perspective strengthens associations between a targeted outgroup and the self, which, in turn, enables more positive automatic intergroup evaluations. In fact, because most people's self-associations are positive, this associative link, in general, generates greater positivity toward the outgroup. As a result of this increased self-outgroup overlapping, implicit intergroup evaluation seems to be more positive. ${ }^{2,15}$

Perspective taking can thus play a significant role in negotiating intergroup conflicts. More specifically, when mediation is adopted as the resolution strategy, perspective taking can boost the efficacy of this process, which is a very effective tool adopted to face common (tractable) conflicts and even to contain the harmful consequences of intractable intergroup conflicts. ${ }^{27}$

\section{The study}

The aim of this study was to investigate the role of perspective taking in the mediation process during an attempted intergroup conflict resolution. It is hypothesized that assuming the competitor's point of view might be a psychological process that fosters the reestablishment of a cooperative setting. In addition, the presence of a mediator should facilitate the resolution, something that should be more evident when participants assume the competitor's perspective.

\section{Materials and methods Participants}

A total of 160 graduate students in psychology (33 men and 127 women; age: $\mathrm{M}=28.8 ; \mathrm{SD}=3.2$ ) took part in the experiment on a voluntary basis and were randomly assigned to one of the conditions of a 2 (conflict: presence vs absence) $\times$ 2 (perspective taking: presence vs absence) $\times 2$ (mediation: presence vs absence) between-subjects experimental design.

\section{Ethics approval and consent to participate}

The ethics committee of the Department of Psychological, Pedagogical and Educational Sciences, University of Palermo, Italy, reviewed the methods of the study and approved it. All procedures performed in studies involving human participants were in accordance with the ethical standards of the 1964 Declaration of Helsinki. Written informed consent was obtained from all individual participants included in the 
study. Participants were debriefed about the study's purpose and were informed that they could withdraw from participation at any time and without any consequences.

\section{Procedure and measures}

All participants were run individually. They were invited to take part in the experiment without knowing the real aim of the study. At the end of the experiment, all participants were thoroughly debriefed and then thanked for their participation.

The experimental procedure consisted of an epistolary exchange between two people, a medical doctor and a psychologist (the participant him/herself). Participants read an excerpt of what they believed was a true interview with a medical doctor, who was named "Dr Mario Rossi" for privacy reasons. In the experimental conditions in which the conflict was present, Mario Rossi used harsh tones, and he strongly discredited psychologists' work while praising the role of medical doctors in treating mental illness. In the experimental conditions in which the conflict was absent, Mario Rossi used mostly positive arguments when he referred to psychologists and appreciated their contributions in treating mental illness. The participants, who were all graduate students in psychology, were asked to pay attention to the interview and then write a reply to Dr Mario Rossi describing the psychologists' points of view. A feeling thermometer, with a scale ranging from 0 to 100 , was used to assess the intensity of the hostility created.

The second variable of the experiment was mediation. An associate of the experimenter was trained to act as a conflict mediator and took part in all of the experimental situations in which an attempt at conflict mediation was present. Thus, mediation accompanied half of the conditions with conflict and half of the conditions without conflict. In the conditions in which mediation was absent, participants wrote the answer to Mario Rossi's interview alone.

Table I Mean and standard deviation of hostility scores

\begin{tabular}{llllll}
\hline Conflict (C) & $\begin{array}{l}\text { Mediation } \\
\text { (M) }\end{array}$ & $\begin{array}{l}\text { Perspective- } \\
\text { taking (P) }\end{array}$ & Mean & N & SD \\
\hline C presence & M presence & P presence & -4.205 & 20 & 0.7763 \\
& & P absence & -1.800 & 20 & 0.4413 \\
& M absence & P presence & -3.055 & 20 & 0.6378 \\
& & P absence & 0.165 & 20 & 0.1785 \\
C absence & M presence & P presence & -0.355 & 20 & 0.4123 \\
& & P absence & -0.130 & 20 & 0.3011 \\
& M absence & P presence & -0.200 & 20 & 0.2956 \\
& & P absence & -0.220 & 20 & 0.4150 \\
\hline
\end{tabular}

To manipulate perspective taking, we adopted the procedure originally developed by Galinsky and Moskowitz. ${ }^{2}$ In the condition with a presence of perspective taking, the participants were asked to put themselves in their counterparts' shoes. In the condition with an absence of perspective taking, this request was omitted.

After experimental manipulations, the feeling thermometer was administered once again.

\section{Results}

\section{Manipulation check}

Analyses of variance (ANOVA) revealed that the participants in the conflict condition had experienced more increased feelings of hostility against the doctor $(\mathrm{M}=4.67, \mathrm{SD}=1.36)$ than the participants in the conflict-absent condition $(\mathrm{M}=3.67$, $\mathrm{SD}=1.86), F(1,109)=6.38, P=0.013$. The experimental procedure thus succeeded in producing an intergroup conflict situation.

\section{Measure of hostility}

In all experimental conditions, hostility was assessed twice with the same instrument - a thermometer. For each participant, the dependent variable's value was calculated as the difference in hostility between the first measurement (before treatments) and the second one (after treatments). In this way, positive values indicated a decrease of hostility, while negative values indicated an increase.

Data distribution of the average hostility scores was analyzed by looking at the skewness and kurtosis indexes. The results showed a normal univariate distribution with an asymmetry value of -0.91 and kurtosis of $-0.16 .^{28}$

A 2 (conflict) $\times 2$ (perspective taking) $\times 2$ (mediation) between-groups ANOVA was conducted to compare the average hostility levels across the conditions. The mean and standard deviation values are reported in Table 1.

The results showed significant main effects of conflict, $F(1,159)=727.02, P<0.001$; mediation $F(1,159)=115.16$, $P<0.001$; and perspective taking $F(1,159)=387.07, P<0.001$. In addition, significant interaction effects were shown between conflict and mediation, $F(1,159)=105.94, P<0.001$; conflict and perspective taking, $F(1,159)=334.54, P<0.001$; and conflict, mediation, and perspective taking, $F(1,159)=12.80$, $P<0.001$, and the interaction effect between mediation and perspective taking was not significant, $F(1,159)=3.7, P=0.074$.

Because we were mainly interested in the effects of mediation and perspective taking in overt intergroup conflict, the conditions in which conflict was present or absent were also analyzed separately. The results showed that, in the 
absence of intergroup conflict, neither mediation, $F(1,79)$ $=0.16, P=$ ns, nor perspective taking, $F(1,79)=1.62, P=$ ns, produced main effects or interactions, $F(1,79)=2.31, P=$ ns. On the other hand, in the presence of conflicts between psychologists and medical doctors, the results showed a significant main effect of both mediation, $F(1,79)=157.01$, $P<0.001$, and perspective taking, $F(1,79)=511.97, P<0.001$, and a significant interaction effect between these two variables, $F(1,79)=10.75, P<0.01$. Looking more closely at the mean scores, it may be observed that perspective taking may effectively reduce intergroup conflict and that its effect is amplified by mediation (Figure 1).

In summary, the results show that in conflict situations, a mediation process may decrease the level of hostility among the parts in conflict and that this result can be magnified when one can assume the perspective of the counterpart.

\section{Conclusion}

In the last two decades, several authors have looked at the role of perspective taking in decreasing the amount

A

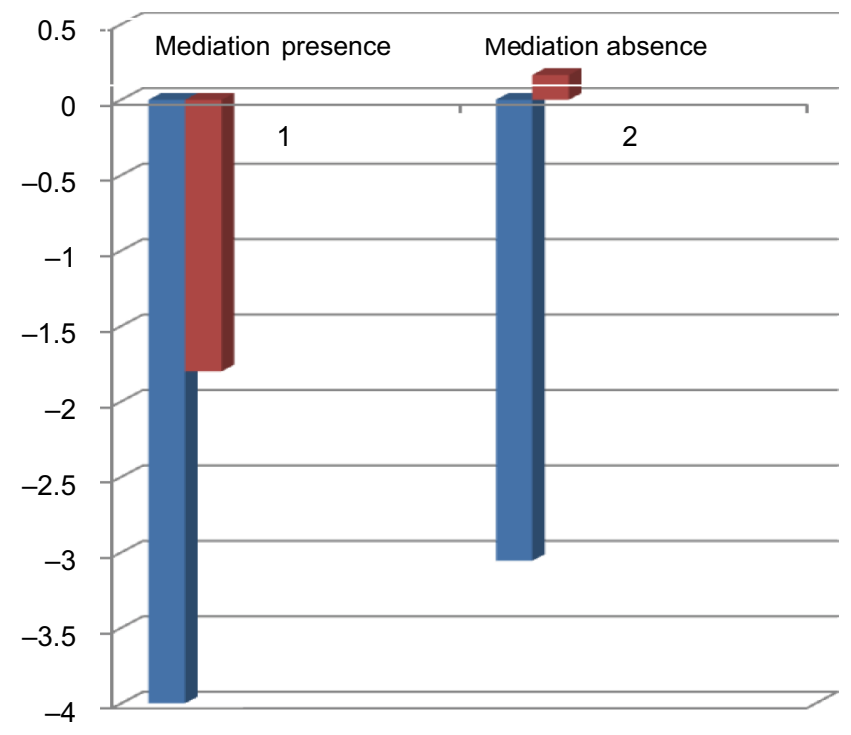

- Perspective taking presence

- Perspective taking absence

B

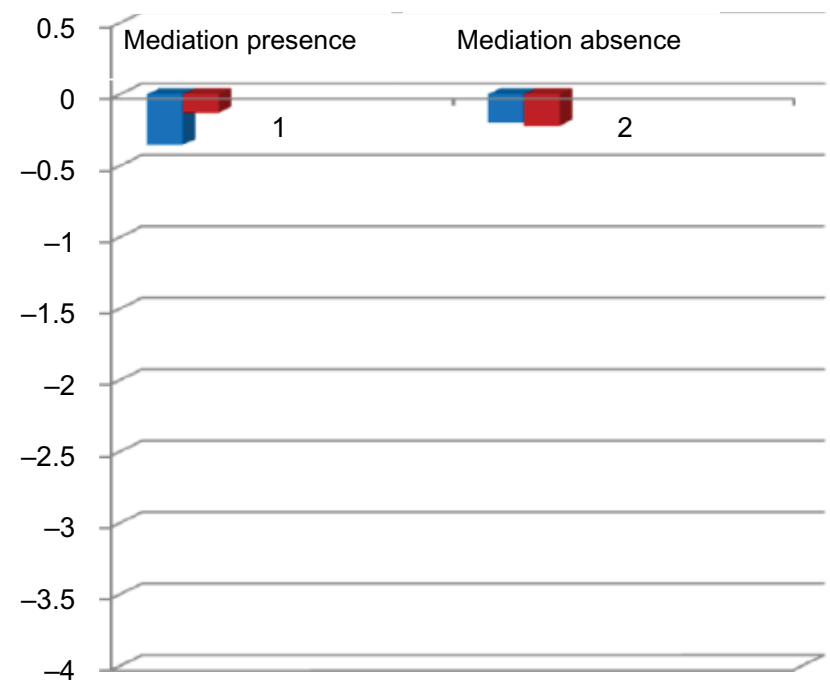

Perspective taking presence

- Perspective taking absence

Figure I Mean of the hostility scores in conditions of conflict presence (A) and absence (B). 
of bias associated with stereotyping and intergroup relations. $^{2,12,29,30}$

These researchers have shown that perspective taking is a suitable approach to obtaining a better social judgment of the outgroup and proved that perspective taking reduces stereotypical expressions and diminishes the accessibility of the stereotyped category.

To this end, this study's rationale was to assess whether perspective taking facilitates a mediation process set to reduce hostility between two groups. The analysis of the roles of perspective taking and mediation showed that both variables were able to reduce hostility. Moreover, the level of hostility was further reduced when perspective taking accompanied mediation. Thus, perspective taking might function as a critical factor in the treatment of intergroup conflict, particularly when mediation is adopted as the treatment strategy.

Therefore, perspective taking not only seems to be a necessary condition to reduce the stereotypes and prejudices that could interfere with a successful mediation process but it may also empower good relations between the involved parties and reorganize dysfunctional rules that permeate an hostile social environment.

\section{Limitations}

This work undoubtedly has limitations. The experimental procedure gave rise to an artificial and controllable conflict in which participant's counterpart was always physically absent. The procedure, in fact, required the assumption of perspective to be suggested by the mediator only to the participant, as Dr Rossi (the counterpart) was absent, and his point of view was accessible through the report of an interview. In this way, it can be said that the assumption of the perspective was one-sided. In a real mediation context, the mediator generally does not act in a unilateral way; instead, he/she should drive each conflicting part to assume the point of view of the other one. Thus, it may be premature to generalize these results to any overt intergroup conflict, as timing and context matter in ways that are not captured by the procedure of this study. At the same time, these findings have theoretical implications, especially in regard to the joint effect of mediation and perspective taking. They seem to be something more than two different tools that can be extracted from the toolbox when needed. Their joint effect cannot be reduced to the sum of the effect of the two strategies. Instead, being invited to assume the counterpart's point of view magnifies the effect of mediation. Thus, it is very important that the mediator possesses the appropriate skills to make the groups in conflict understand each other's points of view and reestablish an effective communication flow based on a mutual understanding free of prejudice.

\section{Disclosure}

The authors report no conflicts of interest in this work.

\section{References}

1. Davis MH. Measuring individual differences in empathy: evidence for a multidimensional approach. J Pers Soc Psychol. 1983;44(1):113-126.

2. Galinsky AD, Moskowitz GB. Perspective-taking: decreasing stereotype expression, stereotype accessibility, and in-group favoritism. J Pers Soc Psychol. 2000;78(4):708-724.

3. Piaget J. The Moral Judgment of the Child. London: Kegan, Paul, Trench \& Trubner; 1932.

4. Batson CD. The Altruism Question: Toward a Social-Psychological Answer. Hillsdale, NJ: Erlbaum; 1991.

5. Batson CD. Altruism and prosocial behavior. In: Gilbert DT, Fiske ST, Lindsey G, editors. The Handbook of Social Psychology. Boston: McGraw Hill; 1998:282-316.

6. Scaffidi Abbate C, Ruggieri S. The fairness principle, reward, and altruistic behavior. J Appl Soc Psychol. 2011;5:1110-1120.

7. Gendolla GHE, Wicklund RA. Self-focused attention, perspectivetaking, and false consensus. Social Psychology. 2009;40:66-72.

8. Scaffidi Abbate C, Boca S, Gendolla GHE. Self-awareness, perspectivetaking, and egocentrism. Self Identity. 2016;15(4):371-380.

9. Baron-Cohen S. Mindblindness: An Essay on Autism and Theory of Mind. Cambridge, MA: Bradford Books, MIT Press; 1995.

10. Richardson DR, Hammock GS, Smith SM, Gardner W, Signo M. Empathy as a cognitive inhibitor of interpersonal aggression. Aggress Behav. 1994;20(4):275-289.

11. Bazerman MH, Neale MA. Heuristics in negotiation: limitations to effective dispute resolution. In: Arkes HR, Hammond KR, editors. Judgment and Decision Making: An Interdisciplinary Reader. New York: Cambridge University Press; 1986:311-321.

12. Galinsky AD, Ku G. The effects of perspective-taking on prejudice: the moderating role of self-evaluation. Pers Soc Psychol Bull. 2004;30(5):594-604.

13. Batson CD, Early S, Salvarani G. Perspective taking: imagining how another feels versus imaging how you would feel. Pers Soc Psychol Bull. 1997;23(7):751-758.

14. Dovidio JF, Ten Vergert M, Stewart TL, et al. Perspective and prejudice: antecedents and mediating mechanisms. Pers Soc Psychol Bull. 2004;30(12):1537-1549.

15. Todd AR, Bodenhausen GV, Galinsky AD. Perspective taking combats the denial of intergroup discrimination. J Exp Soc Psychol. 2012;48(3):738-745.

16. Todd AR, Bodenhausen GV, Richeson JA, Galinsky AD. Perspective taking combats automatic expressions of racial bias. J Pers Soc Psychol. 2011;100(6):1027-1042.

17. Todd AR, Burgmer P. Perspective taking and automatic intergroup evaluation change: testing an associative self-anchoring account. J Pers Soc Psychol. 2013;104(5):786-802.

18. Todd AR, Galinsky AD. Perspective-taking as a strategy for improving intergroup relations: evidence, mechanisms, and qualifications. Soc Personal Psychol Compass. 2014;8(7):374-387.

19. Fisher R, Ury W. Getting to Yes. Boston: Houghton Miffl; 1981.

20. Galinsky AD, Mussweiler T. First offers as anchors: the role of perspective-taking and negotiator focus. J Pers Soc Psychol. 2001;81(4): 657-669.

21. Galinsky AD, Maddux WW, Gilin D, White JB. Why it pays to get inside the head of your opponent: the differential effects of perspective taking and empathy in negotiations. Psychol Sci. 2008;19(4):378-384.

22. Pruitt DG. Strategic choice in negotiation. Am Behav Sci. 1983;27(2): 167-194. 
23. Walton RE, McKersie RB. A Behavioral Theory of Labor Negotiations. New York: McGraw-Hill; 1965.

24. Batson CD. Altruism in Humans. New York: Oxford University Press; 2011.

25. Esses VM, Dovidio JF. The role of emotions in determining willingness to engage in intergroup contact. Pers Soc Psychol Bull. 2002;28(9):1202-1214.

26. Vescio TK, Sechrist GB, Paolucci MP. Perspective taking and prejudice reduction: the mediational role of empathy arousal and situational attributions. Eur J Soc Psychol. 2003;33(4):455-472.

27. Bar-Tal D. Intractable Conflicts: Socio-Psychological Foundations and Dynamics. Cambridge: Cambridge University Press; 2013.
28. Muthén B, Kaplan D. A comparison of some methodologies for the factor analysis of non-normal Likert variables. Br J Math Stat Psychol. 1985;38(2):171-189.

29. Galinsky AD. Creating and reducing intergroup conflict: the role of perspective-taking in affecting outgroup evaluations. In: Mannix NMA, Mannix EA, Sondak H, editors. Toward Phenomenology of Groups and Group Membership. Greenwich, CT: JAI; 2002: 85-113.

30. Wang CS, Kenneth T, Ku G, Galinsky AD. Perspective-taking increases willingness to engage in intergroup contact. PLoS One. 2014;9(1):e85681.

\section{Publish your work in this journal}

Psychology Research and Behavior Management is an international, peerreviewed, open access journal focusing on the science of psychology and its application in behavior management to develop improved outcomes in the clinical, educational, sports and business arenas. Specific topics covered in the journal include: Neuroscience, memory and decision making; Behavior modification and management; Clinical applications; Business and sports performance management; Social and developmental studies; Animal studies. The manuscript management system is completely online and includes a very quick and fair peer-review system, which is all easy to use. Visit http://www dovepress.com/testimonials.php to read real quotes from published authors. 